\title{
Pneumomediastinography in carcinoma of the oesophagus
}

\author{
EMIL HOLUB AND CYRIL S̆IMEČEK \\ From the 1st Surgical Clinic and the Department of Pulmonary Diseases, Palacky University, Olomouc, \\ Czechoslovakia
}

\begin{abstract}
Forty-one patients with carcinoma of the gullet and oesophagogastric junction have been investigated by means of a new pneumomediastinographic method of pertracheal insufflation. More than 1,600 patients suffering from various pulmonary or mediastinal lesions have undergone this simple time-saving procedure. Pneumomediastinography cannot replace radiography of the gullet or oesophagoscopy in cases of cancer of the oesophagus. Since it reveals valuable details, which remain hidden in conventional radiographs or during oesophagoscopy, it may complement the findings of two traditional methods of investigation. The main advantages of pneumomediastinography in the diagnosis of cancer of the gullet are: it permits accurate assessment of the size and shape of the tumour ; in patients submitted to radiotherapy, the local response to this treatment may be determined by changes in the size of the tumour shadow in pneumomediastinal tomograms; it establishes reliably that the tumour does not invade the adjacent organs; it facilitates visualization of some of the enlarged lymph nodes in the mediastinum which are not visible in conventional radiographs or tomograms; and the radiological characteristics of these lymph nodes facilitate an approximate differentiation between inflammatory and metastatic enlargements.
\end{abstract}

The diagnosis of carcinoma of the oesophagus is usually confirmed by two methods of investigation, each more than 70 years old-radiography of the gullet and oesophagoscopy. By these means information is obtained concerning the inner surface of the oesophageal wall only, whereas the changes in the outer surface of the viscus remain concealed. This does not matter much in functional disorders of the oesophagus, but when oesophageal tumours are present important information, such as the size and shape of the tumour and the presence of local invasion or of enlarged mediastinal lymph nodes, cannot be obtained by these two traditional methods.

Mediastinoscopy is one of the more recent diag. nostic methods (Akovbiantz, Aerberhard, and Linder, 1965 ; Specht, 1965) but is rather timeconsuming and not entirely without risk for the patient. There is another simple and safe method which does not require special surgical training or expensive technical equipment-diagnostic pneumomediastinography (Condorelli, 1936). This represents a different method of investigating mediastinal organs and is helpful in solving numerous diagnostic problems there. Bétoulières (Bétoulières, Paleirac, and Thévenet, 1952), one of the pioneers of pneumomediastinography, suggested that this might also be useful for assessing various oesophageal lesions. The idea has not proved popular, for we know of only two papers on this subject (Svoboda and Venclík, 1955; Teichmann, Borek, Stašek, and Valkó, 1960). Pneumomediastinography provides good visualization of all mediastinal organs, including the oeosophagus, which, unless filled with barium, remains invisible in conventional radiographs. Here we suggest that this method helps in the diagnosis of cancer of the oesophagus, particularly as a complement to radiological and oesophagoscopic findings.

\section{MATERIAL AND METHOD}

During the last seven years pneumomediastinography has been performed in 41 patients with carcinoma of the oesophagus and the oesophagogastric junction. In this series 21 patients were inoperable and underwent radiotherapy only, but 20 patients had an operation, in eight instances a radical one (Table I). The pneumomediastinographs were matched against conventional contrast medium studies and oesophagoscopic findings in all the cases. against gross specimens and local findings during 
T A B L E

SERIES OF 41 PATIENTS WITH CARCINOMA OF THE OESOPHAGUS

\begin{tabular}{|c|c|c|c|}
\hline Site & $\begin{array}{l}\text { No. of } \\
\text { Cases }\end{array}$ & $\begin{array}{c}\text { Radical } \\
\text { Operation }\end{array}$ & $\begin{array}{c}\text { Palliative } \\
\text { Procedure or } \\
\text { Exploration }\end{array}$ \\
\hline $\begin{array}{l}\text { Cervical oesophagus } \\
\text { Thoracic oesophagus } \\
\text { Middle } . . \\
\text { Lower } \ldots \\
\text { Oesophagogastric junction }\end{array}$ & $\begin{array}{r}1 \\
26 \\
8 \\
6\end{array}$ & $\begin{array}{l}5 \\
2 \\
1\end{array}$ & $\begin{array}{l}8 \\
2 \\
2\end{array}$ \\
\hline Total .. & 41 & 8 & 12 \\
\hline
\end{tabular}

thoracotomy in eight cases, and against necropsy findings in seven cases.

Pneumomediastinography has been described in detail elsewhere (Pěgřim, Ríha, and Simeček, 1956; Simeček, 1956), and we still use the original method of pertracheal insufflation, easily performed during bronchoscopy, bringing no discomfort to the patient and possible to perform on an out-patient basis. In more than 1,600 investigations of various pulmonary and mediastinal conditions during the last 12 years there have been no notable side-effects in any patient.

Our method of pneumomediastinography consists of three main steps. We begin with bronchoscopy, looking particularly for signs of compression or tumour invasion in the airways, especially in the posterior wall of the trachea and the left main bronchus when cancer of the mid-oesophagus is being considered. When signs of bifurcation lymph node enlargement are encountered, pertracheal aspiration biopsy is performed at the same time for cytological investigation.

The second step consists of insufflation of the mediastinum with oxygen: the bronchoscope is withdrawn $4 \mathrm{~cm}$. above the tracheal bifurcation and a long needle is inserted into the posterior wall of the trachea about $3-4 \mathrm{~cm}$. above the carina. A special device at the end of the needle prevents the bevel from advancing beyond the space between the posterior wall of the trachea and the anterior wall of the oesophagus (Šimeček, 1956; Pěgřim et al., 1956). The proper position of the needle is checked by injecting 1-2 $\mathrm{ml}$. of a $1 \%$ solution of novocain, after which $250 \mathrm{ml}$. of oxygen is insufflated with a normal 50 -ml. syringe within one to three minutes. The needle and bronchoscope are then withdrawn.

The third step follows immediately-tomography of the mediastinum: the tomograms are taken in both the oblique and lateral planes at $1-\mathrm{cm}$. intervals. In nearly all our patients a gulp of barium was swallowed just before tomography was started.

\section{ILLUSTRATIVE CASE REPORTS}

CASE 5 M. B., a 55-year-old man with mild dysphagia for two months, was admitted in November 1963. The barium swallow showed a circular stenotic lesion

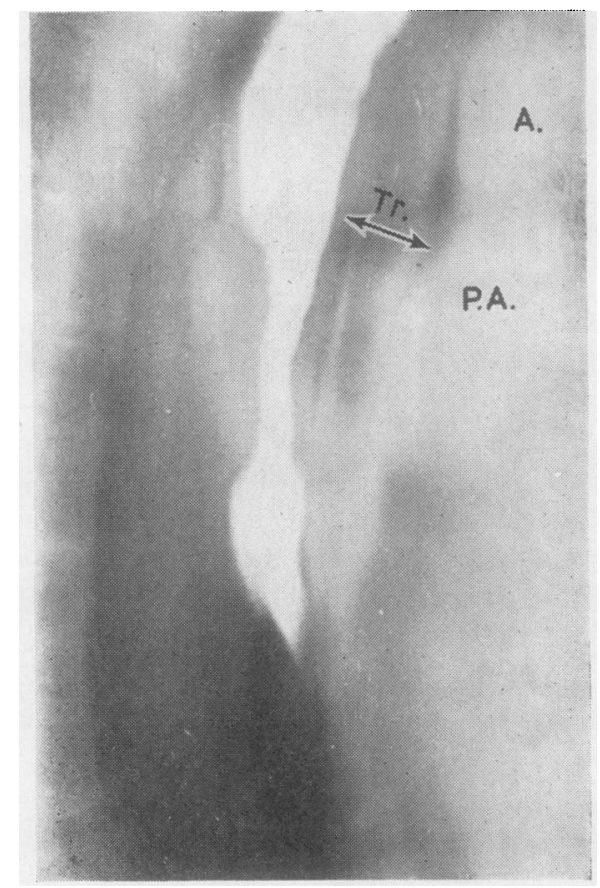

FIG. 1. Case 5. Right oblique view of pneumotomographic study (depth $12 \mathrm{~cm}$.). The gas insufflated into the medias- $\mathbb{Q}$ tinum outlines the external contour of the oesophageal $\overrightarrow{\vec{z}}$ wall thickened by cancerous growth (arrows). A, aorta; P.A., right pulmonary artery; $T r$, trachea.

in the mid-oesophagus. Oesophagoscopy revealed rigidity of the mucosal folds, particularly in the pos-음 terior wall of the gullet at $28 \mathrm{~cm}$. from the upper incisor teeth, and the biopsy showed a squamous- cell carcinoma. Pneumomediastinography $(200 \mathrm{ml}, \underline{3}$. oxygen, Fig. 1), and the outlining of the internal sur- $-\delta$ face of the oesophagus with barium, showed the external contour of the gullet (arrows) and demonstrated a thickening of $0.8 \mathrm{~cm}$. in the anterior wall (arrow) and of $2.8 \mathrm{~cm}$. in the posterior wall (arrow) of the oesophagus $5 \mathrm{~cm}$. in length. Since the insufflated gas surrounded the oesophagus and separated N it from adjacent tissues (arrows), the tumour was restricted to the oesophageal wall only and there was $N$ no local invasion. Shadows cast by the aortic arch, right pulmonary artery, and both walls of the trachea were clearly visible.

On the basis of pneumomediastinography the tumour was considered to be resectable, and retrosternal oesophagocoloplasty as a first-stage operation.was performed. This patient died of cardiocirculatory insufficiency on the second post-operative day. Necropsy confirmed the pneumomediastinographico findings, especially the size of the tumour and the $\stackrel{\odot}{\circ}$ absence of local invasion. 
CASE 7 S. V., a 49-year-old man with dysphagia for six weeks, was admitted in December 1963. The barium swallow showed a circular stenotic lesion of the oesophagus at the level of the aortic arch with dilatation of the oesophageal lumen above the stricture. Oesophagoscopy demonstrated submucosal infiltration of the oesophageal wall with rigidity and hypertrophy of the mucosal folds at 25 $\mathrm{cm}$. from the upper incisor teeth, and the biopsy showed squamous-cell carcinoma. Pneumomediastinography (250 ml. oxygen, Fig. 2) allowed visualization of the outer surface of the anterior (arrow $a$ ) and posterior (arrow b) oesophageal walls. The shadow cast by tumour infiltration of the oesophageal wall was $7 \mathrm{~cm}$. by $0.3 \mathrm{~cm}$. (arrow a) by $2 \mathrm{~cm}$. (arrow $b$ ). Since the insufflated gas surrounded completely the outer surface of the gullet (arrows), no local invasion was thought to be present. In addition, an enlarged retro-oesophageal lymph node was well seen. The enlargement of this lymph node was probably due to reactive hyperplasia, for the shadow cast by it was elongated and without sharp outlines.

On the basis of pneumomediastinography the cancer was considered to be resectable and retrosternal oesophagocoloplasty was performed as a firststage procedure. Unfortunately, the patient refused

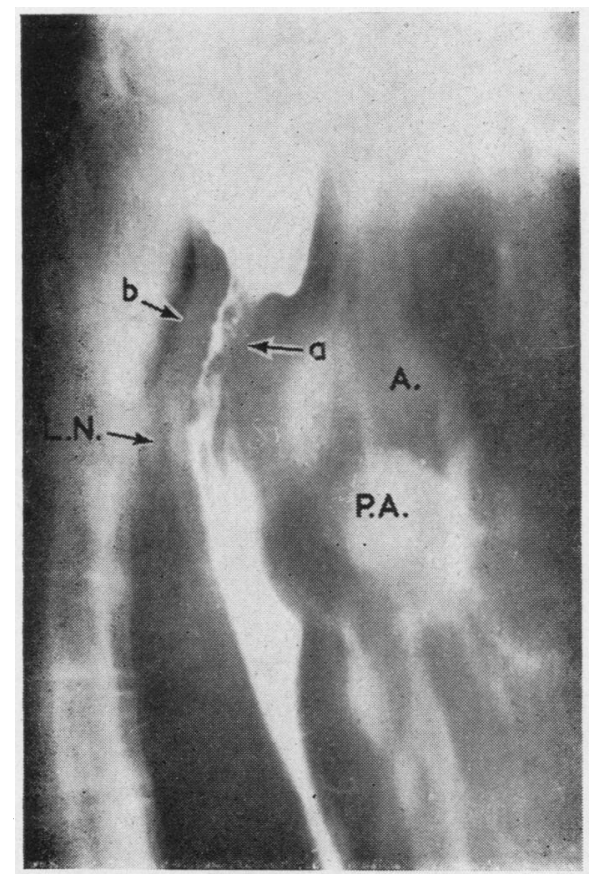

FIG. 2. Case 7. Pneumotomographic study in the right oblique position (depth $13 \mathrm{~cm}$.). Arrows indicate the external surface of the tumour. L.N., retro-oesophageal lymph node enlarged by reactive hyperplasia; A., aortic arch; P.A., pulmonary artery. to undergo the planned radical extirpation of the oesophagus and he died one year later.

CASE 30 This 53-year-old man was admitted in April 1960 complaining of dysphagia of 3 months' duration. A barium swallow showed large irregularities and filling defects in the lower third of the gullet transgressing as far as the oesophagogastric junction (Fig. 3). Oesophagoscopy revealed carcinomatous cauliflower fungations partially obliterating the distal third of the oesophagus which proved malignant on biopsy. Pneumomediastinography (200 ml. oxygen) was performed (Fig. 4). The insufflated gas allowed visualization of the external wall of the proximal half of the oesophagus as far as the level of the ligamentum arteriosum, which was seen between the aorta and the pulmonary artery. From here downward an enormous shadow of hourglass form was seen: the upper part of this shadow represented a giant cluster of lymph nodes enlarged by metastases. This cluster, not visible in the conventional barium study, had caused deviation of the oesophagus (Fig. 3). The lower part of the shadow was the large tumour which was not separated from adjacent tissues by insufflated gas.

The lesion was considered to be inoperable. We were able to verify the pneumomediastinographic findings at necropsy since the patient died two months later of hepatic insufficiency from extensive metastatic carcinoma in the liver.

\section{RESULTS}

Three important data, not found by traditional methods of investigation, were obtained by pneumomediastinography: the shape and size of the tumour, the absence of local invasion, and the presence of enlarged lymph nodes.

The size of the tumour could be determined and measured on the basis of pneumotomography in all but two (technically inadequate tomograms) of our patients. Our resectable cases showed in the pneumotomograms a growth usually of less than $5 \mathrm{~cm}$. in length and $2 \mathrm{~cm}$. in width. The ability to measure the size of the growth had other advantages. In the follow-up of four patients to whom pre-operative radiotherapy had been given, the response to radiation could be estimated on the basis of the changes in the size of the tumour shadow in the pneumotomograms. A considerable decrease in size of the growth (more than $3 \mathrm{~cm}$. in length and $0.5 \mathrm{~cm}$. in width) could be seen in three of these cases.

Local invasion was assessed by pneumotomograms, and sometimes helped to establish reliably that the tumour did not invade the surrounding organs or tissues (Figs 1 and 2). Six of our eight patients in this category were subjected to radical 


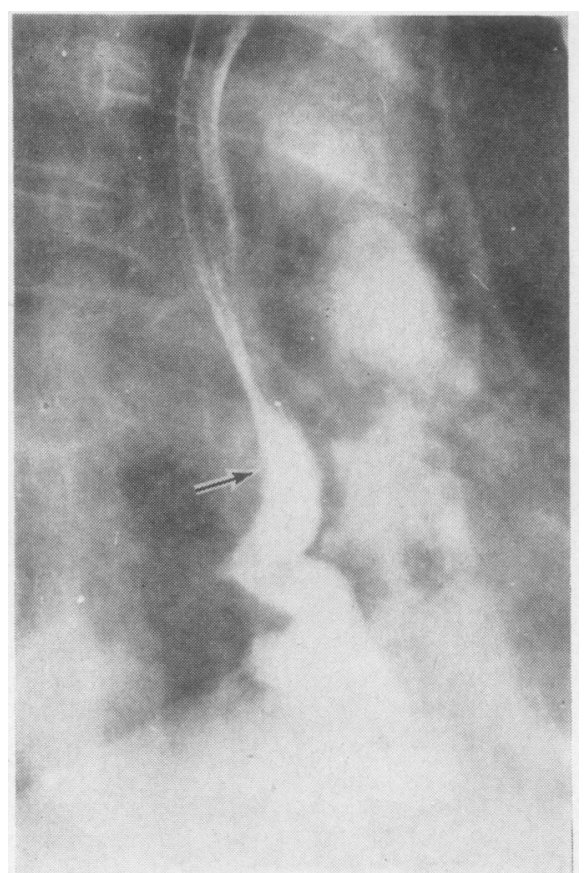

fIG. 3. Case 30. Barium contrast radiograph. Cancer of the lower third of the gullet. The cause of the deviation of the oesophagus (arrow) is not seen.

surgery. We could not distinguish local invasion from perioesophageal inflammatory adhesions in cases where the gas insufflated into the mediastinum did not separate the tumour shadow from adjacent tissues, and in three of our patients with oesophageal cancers above the bifurcation it provoked forward bulging of the posterior wall of the trachea. In such cases the insufflated gas did not separate the tumour shadow from the posterior wall of the trachea; however, invasion was present in only two patients; the third case was resectable. It should be mentioned that in the latter case the absence of invasion was diagnosed pre-operatively by cytological investigation of the material obtained during bronchoscopy by puncture biopsy of the posterior wall of the trachea.

Pneumomediastinography also enabled us to visualize the enlarged lymph nodes in the mediastinum, which are not visible in conventional radiographs (Figs 2, 4, and 6). In 20 of our patients, mostly with cancer localized in the midoesophagus, enlarged lymph nodes could be demonstrated. We were able to estimate not only the size and position of these but also to carry out an approximate differentiation between metastatic enlargement (Figs 4 and 6) and lymph node hyperplasia (Fig. 2) according to the radiological characteristics.

\section{DISCUSSION}

The diagnosis of carcinoma of the oesophagus is, in the first instance, almost always determined radiologically. The increasing demand for more diagnostic information brought about by advances in surgery of the oesophagus evoked a need for information about the actual extent of longitudinal and transverse invasive growth of the cancer, the presence or absence of direct invasion into the mediastinal organs, and the regional lymph node spread. In our opinion, pneumomediastinography allows such information to be obtained in a simple manner and without notable risk for the patient.

In the pneumomediastinogram, the normal oesophagus, when not filled with barium, appears in the gas-filled prevertebral area as a band-like shadow running up along the trachea and down along the aorta. Its outer surface is well visualized

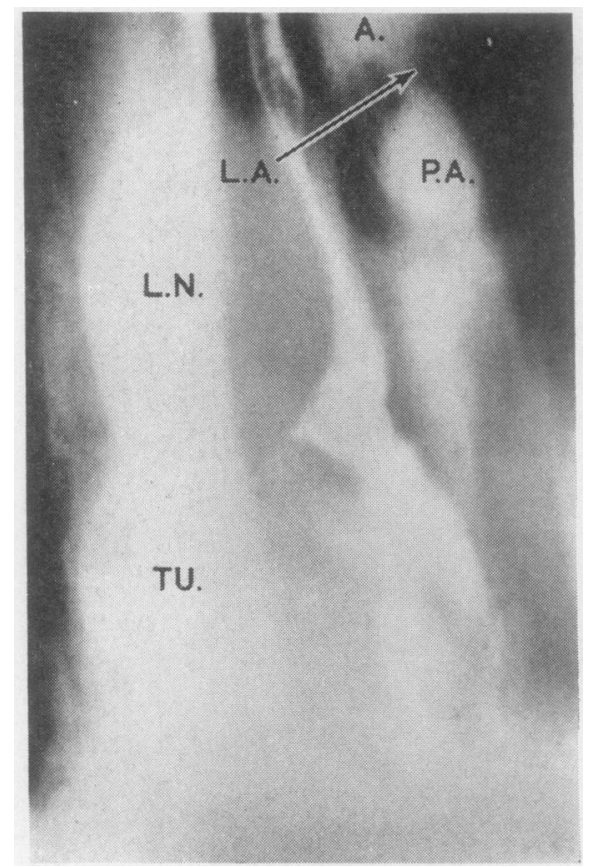

FIG. 4. Case 30. Pneumotomographic study in the right oblique position (depth $11 \mathrm{~cm}$.). L.N., a giant cluster of lymph nodes enlarged by metastases; TU., the actual oesophageal cancer; L.A., ligamentum arteriosum; A., aorta; P.A., pulmonary artery. 


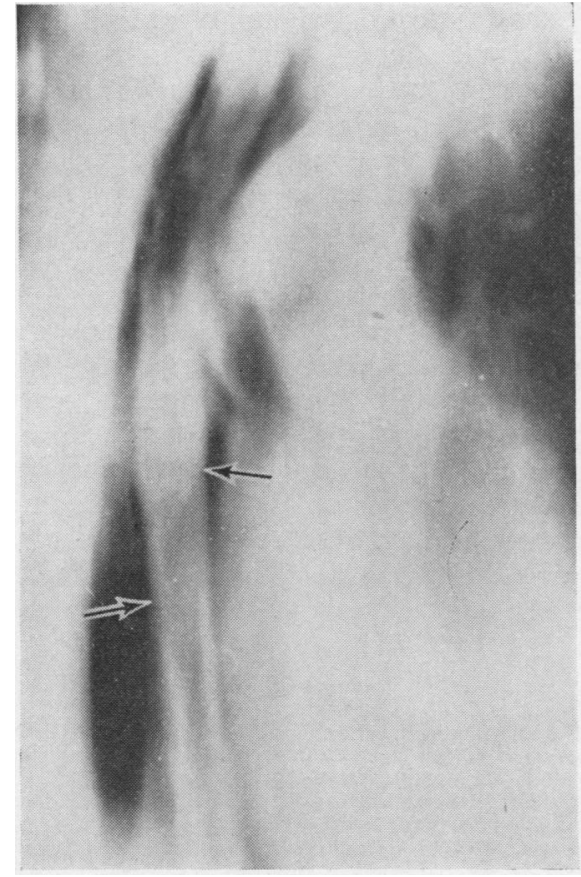

FIG. 5. Pneumotomographic study of a normal oesophagus of a 60-year-old man in the right oblique position (without barium filling, depth $12 \mathrm{~cm}$.). The outer surface of the whole thoracic oesophagus in the gas-filled pre-vertebral area is well demonstrated (arrows).

because the gas which forms a sharp negative contrast delineates the shadow cast by the viscus (Fig. 5). When the oesophagus is filled with barium the inner surface of the oesophageal wall is also outlined.

By this method there may be a more accurate diagnosis of oesophageal cancer. In the early stages of cancer the radiological and endoscopic diagnosis may be extremely difficult, and then the slight thickening of the oesophageal wall which can be detected only in pneumotomograms may be helpful, as we found in three cases of small infiltrating cancers.

On the other hand, in large advanced tumours, where the radiographic and oesophagoscopic findings are conclusive, this method tells us accurately the size of the cancer, which may be of help therapeutically. After radiotherapy, follow-up pneumomediastinography may show the local response to this method of treatment. In addition, the position of the tumour may be determined precisely by means of such landmarks as the aortic arch, pulmonary artery, tracheal bifurcation, both main bronchi, or some- times the last segment of the azygos vein, which are all well visible in pneumotomograms.

Direct invasion of oesophageal cancer is the most important factor affecting the resectability of the tumour. We think that with pneumotomograms we can determine reliably the absence of invasive growth into the mediastinal structures (Figs 1 and 2). When oxygen insufflated into the mediastinum surrounds the whole external surface of the tumorous thickening of the oesophageal wall, seen in the pneumotomograms as a narrow strip of negative contrast outlining the outer side of the tumorous shadow and separating it from adjacent organs, there should not be any local invasion present and the cancer should be restricted to the viscus only. We consider such cases to be resectable, but naturally only when there are no other contraindications to radical surgery.

Sometimes gas insufflated into the mediastinum does not surround the tumour, and consequently the outline of the tumour shadow is not completely or partially separated from the neighbouring organs. This may be due either to local invasion or to inflammatory adhesions of the tumour to surrounding structures, though unfortunately we could not differentiate between these two.

Solitary metastases to the tributary lymph nodes play a distinct but not decisive role in the operability or the prognosis. However, information about the presence and position of enlarged lymph nodes within the mediastinum is always helpful. With pneumomediastinography we visualized enlarged mediastinal lymph nodes not hitherto amenable to radiographic representation. As already shown in one of our earlier papers (Simeček and Holub, 1966), a mediastinal lymph node must be at least 0.5 to $0.6 \mathrm{~cm}$. in order to be visualized in pneumomediastinograms and to be evaluated as an enlarged lymph node. The quality of visualization of these enlarged lymph nodes depends largely on their position. The paratracheal and tracheobronchial lymph nodes and the lymph nodes around the aortic arch and behind the oesophagus are most readily seen. The latter are best outlined in lateral or oblique views (Figs 2 and 6). Visualization of tracheal bifurcation nodes is less good due to overlapping of the pulmonary artery. In addition, the radiological characteristic of the lymph nodes in pneumotomograms facilitates an approximate differentiation between inflammatory (Fig. 2) and metastatic (Figs 4 and 6) enlargements (Simeček, 1959 ; Simeček, 1960 ; Šimeček and Holub, 1966). 


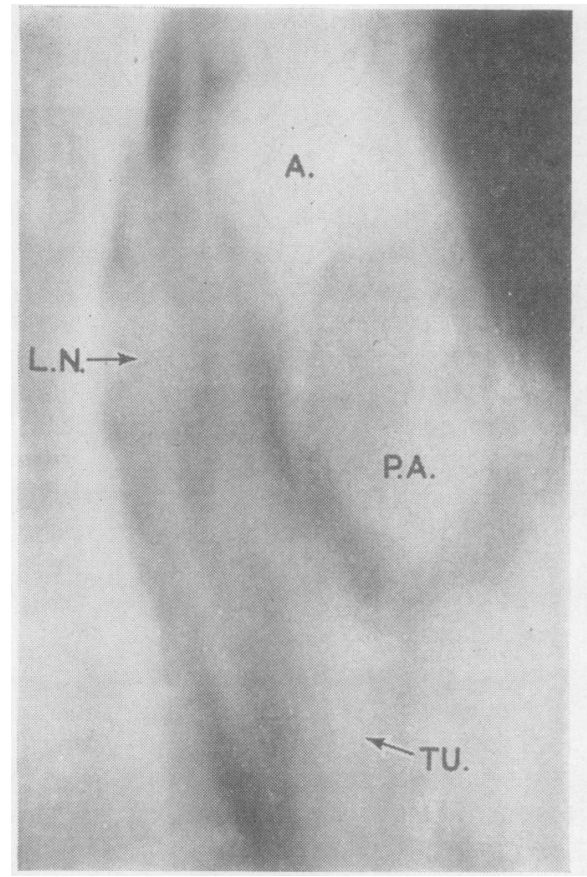

FIG. 6. Case 35. Pneumotomographic study in the right oblique position (without barium filling, depth $13 \mathrm{~cm}$.). $T U$., shadow cast by the cancer of the lower third of the oesophagus. The shadow does not 'separate' from adjacent tissues. L.N., a round, sharp outlined retro-oesophageal lymph node enlarged by metastasis. A., aortic arch; P.A., pulmonary artery.

Bronchogenic carcinoma may sometimes produce dysphagia and be misdiagnosed as malignancy of the gullet. We encountered five such patients in whom the oesophagoscopic and radiological appearance of the gullet favoured oesophageal carcinoma. Pneumomediastinography together with cytological investigation of the material obtained by aspiration biopsy of enlarged bifurcation lymph nodes and the $\vec{F}$ bronchoscopic finding enabled us to diagnose $\frac{7}{0}$ bronchogenic carcinoma. Naturally, these cases are not included in our series.

Pneumomediastinography cannot replace the $\overrightarrow{\mathbb{D}}$ traditional methods of investigation of the oesophagus. But since it reveals some valuable details os which remain hidden in conventional radiographs $\vec{O}$ we suggest this method is adopted not only in clinically obvious cases but in all instances where $\vec{\omega}$ cancer of the oesophagus is suspected. We are well aware that in many countries pneumo- $x$ mediastinography is not so popular, as, for $\underset{\mathrm{N}}{\mathrm{N}}$ instance, in France, Italy, and Czechoslovakia. $\overrightarrow{7}$ However, the purpose of our paper is not to $\checkmark$ exaggerate its diagnostic value but to show how 은 this procedure can help and can complement $\rightarrow$ other methods.

\section{REFERENCES}

Akovbiantz, A., Aerberhard, P., and Línder, E. (1965). Die Medias- $\overrightarrow{\mid}$ tinoskopie in der Operabilitätsbeurteilung bei Oesophaguskarzinom. Schweiz. med. Wschr., 95, 168.

Bétoulières, P., Paleirac, R., and Thévenet, A. (1952). Le pneumomédiastin par voie exo-péritoneale. Presse méd., 60, 1796.

Condorelli, L. (1936). Il pneumo-mediastino artificiale. Minerva med., $27(1), 81$.

Pěgřim, R., Řiha, V., and Šimeček, C. (1956). Le pneumomédiastin par voie pertrachéale. Poumon, 12, 765.

Šimeček, C. (1956). Perbronchiální a pertracheální diagnostické punkce. (Perbronchial and pertracheal aspiration biopsies.) Acta Univ. Palackianae Olomuc., 11, 199.

_- (1959). Tuberkulóza a sarkoidóza nitrohrudních uzlin u dospelých. (Tuberculosis and sarcoidosis of the mediastinal lymph nodes in adults.) Rozhl. Tuberk., 19, 642.

- (1960). Rozdíly $\mathrm{v}$ obrazu zvětŠených mediastinálních uzlin při vyšetření diagnostickým pneumomediastinem. (The differences in the appearances of enlarged mediastinal lymph nodes on the pneumostratigrams.) Ibid., $20,589$.

and Holub, E. (1966). Limits of visualization of mediastinal structures in pneumomediastinography under various pathologic conditions. Acta Univ. Palackianae Olomuc., 40, 257.

Specht, G. (1965). Erweiterte Mediastinoskopie. Thoraxchirurgie, 13, 401.

Svoboda, M., and Venclík, H. (1955). Možnosti pneumomediastina $v$ diagnostice chorob jicnu. (The possibilities of the pneumomediastinography in the diagnosis of the diseases of the esophagus.) Cas. lek. čes., 94, 1335.

Teichmann, V., Borek, Z., Stašek, V., and Valkó, P. (1960). Parieto- O graphie der Speiseröhre als Beitrag zur Differenzialdiagnostik primärer und sekundärer Mediastinalgeschwülste. Neoplasma I (Bratisl.), 7, 193 